\title{
Analysis of studies learning outcomes according to Bloom's taxonomy
}

\author{
Vedran Juričić, Monika Pejičić, Gabrijela Vidaković \\ Department of Information and Communication Sciences \\ Faculty of Humanities and Social Sciences \\ I. Lučića 3, Zagreb, Croatia \\ vjuricic@ffzg.hr, mpejicic@ffzg.hr, gvidakovic@ffzg.hr
}

\section{Summary}

The paper analyses learning outcomes of undergraduate and graduate studies of Faculty of humanities and social sciences, University of Zagreb, and correlates them with the categories of Bloom's taxonomy. By observing the representation of categories in different study programs, the paper analyses the similarities and differences between undergraduate and graduate studies, as well as between single and double major studies.

Keywords: learning outcomes, analysis, correlation, similarity, levels of study

\section{Introduction}

A Learning Outcome is a statement of what a student is expected to know, understand and/or be able to demonstrate after completion of a process of learning [5]. Outcomes may refer to one level of study, one subject or one module, however, they are cumulative and interconnected so that they together contribute to the overall learning outcomes of the study program. Outcomes state the competences of the learning program that can also be used to correlate it with its level in the European Qualifications Framework.

Defining what a student will know or understand is a complex process, especially when it is required to be expressed in a short sentence. Teachers often rely on a certain model that helps them to design, assess, and evaluate student learning [7].

American educational psychologist Benjamin Bloom led a group of educators who studied the thinking process and correlated it with educational goals and objectives [4]. This classification is known as Bloom's taxonomy, a model of ordering and classifying thinking. Bloom identified three domains of educational activities: cognitive, affective and psychomotor.

The cognitive domain involves knowledge and the development of intellectual skills [6]. There are six categories that can be thought of as degrees or difficulties: Knowledge, Comprehension, Application, Analysis, Synthesis and Evaluation. Those categories are successive, the previous one must be mastered before 
the next one can take place. For example, student cannot understand something if he does not first remember it [2].

The affective domain involves changes in feelings, attitudes and values that shape students' thinking and behaviour [9]. It includes the manner in which the students deal with problems emotionally, for example: feelings, appreciation and motivation [1]. There are five categories in affective domain, ordered by the level of complexity: Receiving, Responding, Valuing, Organization and Characterising.

The psychomotor domain includes physical movement, coordination and use of the motor-skill areas [10]. These skills are measured in terms of speed, precision, distance, procedures or techniques in execution. There are seven psychomotor categories, ordered by the level of complexity: Perception, Set, Guided response, Mechanism, Complex overt response, Adaptation and Origination.

Each category (in all three domains) has corresponding action verbs that teachers can use to form learning outcomes. This paper analyses verbs for learning outcomes of studies on Faculty of humanities and social sciences, and analyses the relation between undergraduate and graduate studies, as well as single and double major studies.

\section{Data acquisition and initial processing}

The first step of research was the acquisition of study programs learning outcomes, which was made during the faculty's accreditation process. Learning outcomes were collected for each study program separately using a web application, and then inserted into the database. From total of 138 study programs, there were 16 programs that had no associated learning outcomes and were not taken into further analysis.

Table 1 shows the number of single and double major studies in each level of study. It can be seen that double major studies (form little less than $75 \%$ (90) and that graduate studies form almost $66 \%$ (80) of all studies. The only integral study (undergraduate and graduate) is History and Geography that has no double major variant. This paper observes various differences between levels of study programs, and because the number of integral studies is inadequate for quality analysis, History and Geography was also omitted from analysis. In other words, the research was based on total number of 121 study programs.

Table 1. The structure of study programs

\begin{tabular}{c|ccc|c} 
& Undergraduate & Graduate & Integral & \multicolumn{1}{c}{ Total } \\
\hline Single major & 10 & 21 & 1 & 32 \\
Double major & 31 & 59 & 0 & 90 \\
\hline Total & 41 & 80 & 1 & 122
\end{tabular}


The second step was the acquisition of taxonomy action verbs, which were collected from different internet sources, manuals and literature. They were also loaded into the database and associated with one of the categories in their learning domains: cognitive, affective or psychomotor. Each category was assigned a numerical value that was in later analysis used for calculating the value of learning outcomes. In the remainder of the paper, those categories are referred as levels.

The third step was determination of relationships between outcomes and action verbs. The majority of learning outcomes were associated with only one action verb, in which case they were assigned a numerical value of their action verb. For example, outcome "Analyse the basic concept..." has one action verb, analyse, (cognitive domain, $4^{\text {th }}$ level) and thus its assigned value was 4 .

There were two exceptional cases:

- learning outcome contained more than one action verb, e.g. define and describe concepts...

- learning outcome contained an action verb that existed in more than one level or learning domain, e.g. explain exists in cognitive (Comprehension) and affective domain (Valuing and Organization)

These problems were solved equally: learning outcome was split for each existing verb or level. For example, define and describe concepts was treated as two outcomes, define concepts and describe concepts.

Table 2 shows the statistics of processed learning outcomes. From total of 151 action verbs in cognitive domain, $77.48 \%$ were used in at least one learning outcome. Also, there are 3592 learning outcomes that were classified in cognitive domain because of their relations with cognitive action verbs. The cognitive domain consists of 7 levels, thus the average level can take value from interval $[1,7]$. The calculated value of 3.41 shows that the average level of all study programs is approximately in the middle between Application and Analysis level. Similar applies to the affective domain, where the average level is between Valuing and Organization. The weakest level is found in the psychomotor domain, which was expected because of the field of the observed studies.

Table 2. Action verbs usage and average levels

\begin{tabular}{l|cccc} 
& Total verbs & Used verbs (\%) & Outcomes & Average level \\
\hline Cognitive & 151 & 77.48 & 3592 & $3.41 / 7$ \\
Affective & 129 & 51.94 & 2336 & $3.33 / 5$ \\
Psychomotor & 69 & 42.03 & 825 & $2.68 / 7$
\end{tabular}

\section{The analysis of common outcomes}

A relationship between outcomes and studies was analysed in a way to discover which outcomes are common to all or majority of study programs, i.e. which outcomes are not subject specific. Those outcomes should be generic, which 
means that they are not related to any discipline or field, but to the level of study.

Analysis resulted in a very small number of common outcomes. As it is shown in Table 3, the most frequent outcome appears in less than $19 \%$ of study programs. It is included only in undergraduate studies, which is understandable because it also refers to the selection of further education and future graduate study. The other four most frequent outcomes appear only in teaching-oriented studies.

Table 3. Common learning outcomes

\begin{tabular}{|l|c|}
\hline \multicolumn{1}{|c|}{ Learning outcome } & Percentage \\
\hline $\begin{array}{l}\text { Assess own interests and competencies and select appropriate areas for further } \\
\text { education }\end{array}$ & 18.85 \\
\hline $\begin{array}{l}\text { Prepare and transmit course materials in accordance with the fundamental } \\
\text { articulation models }\end{array}$ & 9.84 \\
\hline $\begin{array}{l}\text { State, explain and apply basic psychological factors of successful learning and } \\
\text { teaching }\end{array}$ & 8.20 \\
\hline $\begin{array}{l}\text { Apply the skills of lifelong learning and language training in certain field, } \\
\text { depending on the needs of the job }\end{array}$ & 5.74 \\
\hline Explain didactic theories and models and apply them in teaching & 5.74 \\
\hline
\end{tabular}

\section{- Undergraduate to graduate $\square$ Study programs}

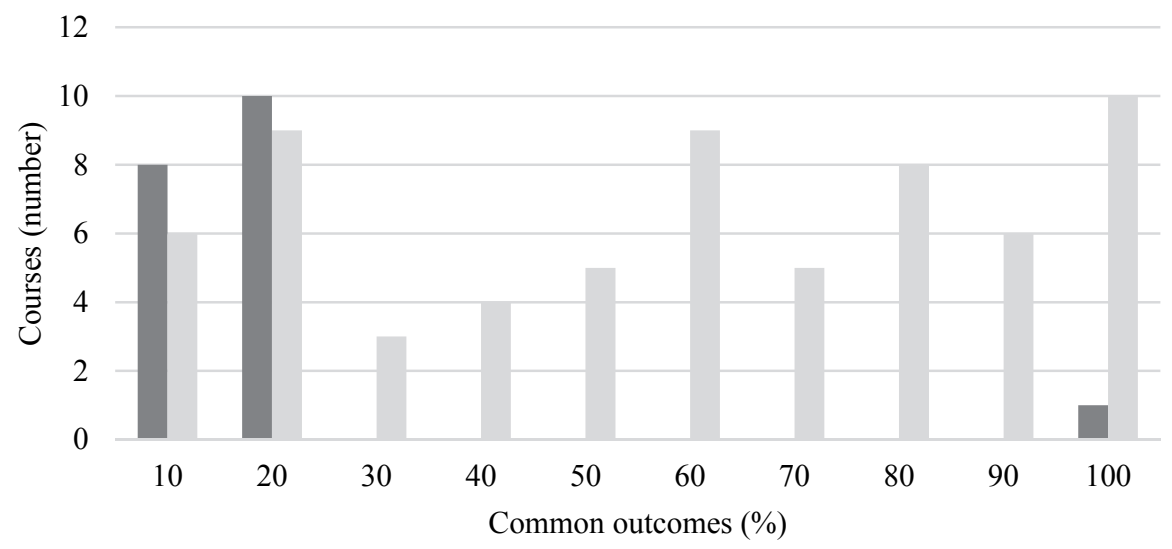

Figure 1: Common outcomes analysis

Data were further analysed for common outcomes between undergraduate and graduate level of each study program (Figure 1, darker fill). Most study programs overlap from $0 \%$ to $20 \%$ of their outcomes, which corresponds to one or two common outcomes. In this interval there is a total of 18 (out of 41) study programs. For example, Undergraduate study of Information sciences and 
Graduate programme of library science overlap in one learning outcome: Implement programs of material and data protection. It is interesting to observe that one study program on graduate level completely overlaps with its undergraduate level.

Figure 1 also shows the overlapping of learning outcomes between study programs of their corresponding study (e.g. Graduate study of Informatics, Teaching-oriented and Research-oriented study). There are 10 study programs with completely overlapping outcomes, 6 study programs with $90 \%$ overlap, etc. There exists a certain regularity: higher similarity level (above 50\%) is noticed only between single and double major variants of the same study program. Other combinations (e.g. between two single major studies) have a lower level of similarity.

\section{Differences between undergraduate and graduate studies}

Undergraduate level of study should be formed in a way that it provides general knowledge in the field of study, that is, students are supposed to gain principles and concepts relating to the field [8]. Graduate level of study provides highly specialized knowledge and students gain specialized skills that enable problem solving, integration with other fields and developing new knowledge [3].

Figure 2 shows the relationship between learning outcome levels in each domain and two observed levels of study. Horizontal axis represents learning outcome levels, and vertical axis shows the percentage of each outcome level in undergraduate or graduate studies.

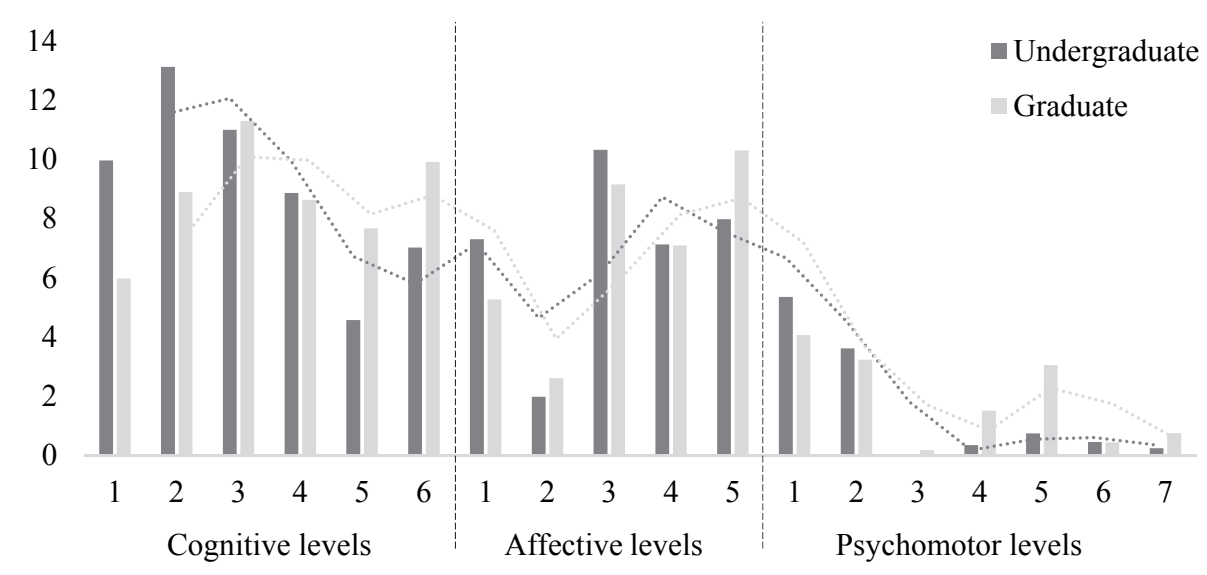

Figure 2: Relationship between outcome levels and study levels

The analysis showed that graduate studies are more represented in higher levels of cognitive domain, i.e. $10 \%$ of their learning outcomes is associated to $6^{\text {th }}$ cognitive level, as opposed to $7 \%$ in the undergraduate studies. Synthesis level 
$\left(5^{\text {th }}\right)$ refers to integrating and combining ideas and knowledge into new ones, and Evaluation level $\left(6^{\text {th }}\right)$ refers to assessment and critique of values and ideas. Both levels are emphasised in graduate studies, which is in accordance with differences between undergraduate and graduate studies (explained in the previous paragraph).

In the affective domain, there exists a very small difference between levels of study. The average level of undergraduate studies is 3.19 , while graduate studies have average level of 3.42. Graduate studies are noticeably more represented only in the $5^{\text {th }}$ level of the affective domain.

As it is shown in Table 2, psychomotor domain is the least represented one, with only $12 \%$ of learning outcomes, versus $53 \%$ in cognitive and $35 \%$ in affective domain. Thus, each increase in action verb usage has strong influence on study level representation in that domain. It is noticeable that graduate studies are more represented from $3^{\text {rd }}$ to $7^{\text {th }}$ level of the psychomotor domain.

Difference in distributions between outcome and study levels is statistically significant; calculated Chi-Square value was 61.95 , which is above the critical value of 26.3 with 16 degrees of freedom. The null hypothesis (there is no difference between distributions) is rejected and the alternative hypothesis (there exists a difference between distributions) is accepted.

\section{Differences between levels of the same study}

Data was also analysed to determine differences between undergraduate and graduate level of the same study (e.g. from Undergraduate study of Information sciences to Graduate study of Informatics - Teaching-oriented study). Values of learning outcomes were summed together for each study level, so study levels could take a value from the interval $[0,15]([0,5]$ cognitive value $+[0,4]$ affective value $+[0,6]$ psychomotor value. The increment was calculated so that the final value of the undergraduate study was subtracted from the final value of graduate study. For example, final value for the Undergraduate study of Information sciences was 7.15, and for the Graduate study of Informatics - Teaching-oriented study was 9.99 (increment is 2.83).

The importance of increment is that it is a measure that shows how much a graduate level of study is above an undergraduate level. In the example above, an increment of 2.83 means that a graduate study is almost 3 levels above an undergraduate study. Those levels can be located within the same domain, but a difference may be caused by any combination of levels.

Maximum determined positive value was 6.69 (almost 7 levels) and maximum negative value was 1.77, which means that undergraduate study is almost 2 levels above graduate study.

Figure 3 shows the number of study programs in each increment interval. It can be seen that there are seven study programs with almost no change in outcome levels, for which the increment takes value between 0 and 0.5 (dashed vertical line). Full vertical line represents an average increment value, which is 1.74. 


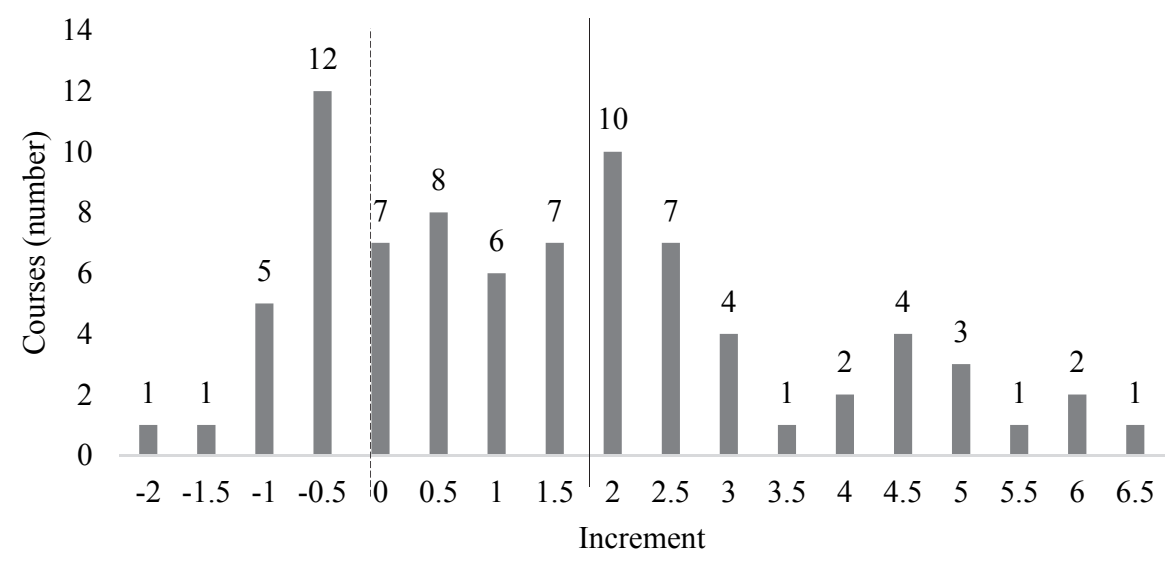

Figure 3: Increments from undergraduate to graduate studies

There are 19 (23\%) courses located left of the dashed vertical line, which means they have negative increment and their graduate level is below their undergraduate level. Detailed analysis showed that the maximum decrement is -1.2 for cognitive, and -1.4 for affective and psychomotor domain.

Still, the majority of studies have a positive increment; $70 \%$ of them have an increment greater than 0.5 . The greatest increment was 6.7 which is quite surprising, as it shows a big leap from undergraduate to graduate level. It is composed of the following increments: 2.27 in the cognitive, 1.00 in the effective and 3.42 in the psychomotor domain.

\section{Differences between single and double major studies}

Double major studies are generally combined with each other to provide students broader view and interconnections between two fields. It is possible that single major students receive better knowledge or competencies than the double major students, as latter gain only half ECTS credits in that field.

Figure 4 shows the differences in study outcomes between single and double major studies. Horizontal axis shows the levels of cognitive, affective and psychomotor domain, and vertical axis shows the number of single or double major studies in each level.

It can be seen that single major studies are more represented in higher levels of cognitive, affective and psychomotor domain. The average cognitive level of single major studies is 3.64, versus 3.32 for double major studies. In other words, single and double major studies differ in only 0.3 cognitive level, which is only a small difference. 


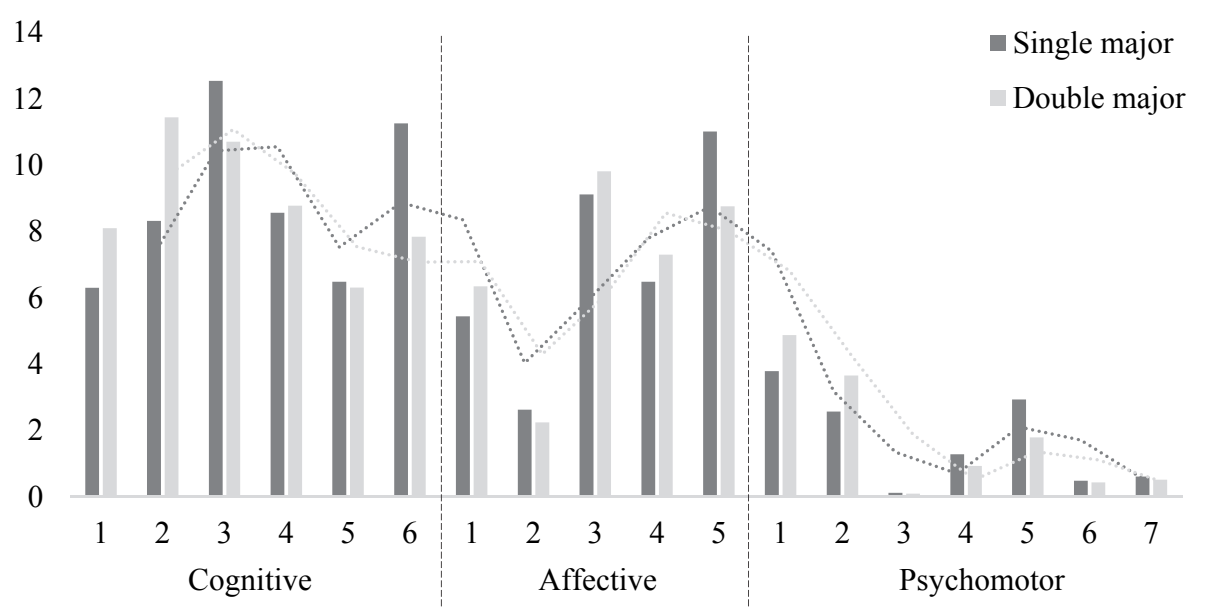

Figure 4: Relationship between single and double major studies

Although a difference between averages of single and double major studies is visually small, a difference in distributions between them is statistically significant; calculated Chi-Square value was 168.73 , which is above critical value of 26.3 with 16 degrees of freedom. The null hypothesis (there is no difference between distributions) is rejected and the alternative hypothesis (there exists a difference between distributions) is accepted.

\section{Conclusion}

The research in this paper is based on more than 6000 learning outcomes and 121 study programs that are offered on Faculty of humanities and social sciences. The paper analyses a relationship between learning outcomes and the levels of cognitive, affective and psychomotor domain, in order to determine their correlation with the undergraduate and graduate studies, and with single and double major studies.

Analysis showed that the differences between undergraduate and graduate studies are statistically significant. Graduate studies are more represented in higher levels of cognitive, affective and psychomotor domain.

Also, there exists a statistically significant difference between single major and double major studies, where single major studies in average have higher levels of learning outcomes.

The future step in research will be directed towards the analysis of learning outcomes of individual courses, especially on the relationship between them and the learning outcomes of their studies. 


\section{References}

[1] Bloom's Taxonomy: The Affective Domain.

http://www.nwlink.com/ donclark/hrd/Bloom/affective_domain.html (20.06.2015.)

[2] Churches, A. Bloom's Taxonomy Blooms Digitally. http://teachnology.pbworks.com/f/Bloom\%5C's+Taxonomy+Blooms+Digitally.pdf (12.06.2015.)

[3] Descriptors defining levels in the European Qualifications Framework (EQF). https://ec.europa.eu/ploteus/content/descriptors-page (23.06.2015.)

[4] Forehand, M. Bloom's Taxonomy: From Emerging Perspectives on Learning, Teaching and Technology. http://www4.edumoodle.at/gwk/pluginfile.php/109/mod_resource/content/5/ forehand_bloomschetaxonomie02.pdf (11.06.2015.)

[5] Kennedy, D. Hyland, A. Ryan, N. Writing and Using Learning Outcomes: a Practical Guide. http://www.procesbolonski.uw.edu.pl/dane/learning-outcomes.pdf (29.09.2015)

[6] Learning Domains or Bloom's Taxonomy.

[7] http://users.manchester.edu/Student/GJTribbett/Webpage/Bloom's\%20Taxonomies.pdf (15.06.2015.)

[8] Levels of study. http://www.makeyourmark.edu.au/study-options/choosing-what-tostudy/levels-of-study/ (24.06.2015.)

[9] Lord, T. Baviskar, S. Moving Students From Information Recitation to Information Understanding: Exploiting Bloom's Taxonomy in Creating Science Questions. Journal of College Science Teaching, 2007.

[10] Neuman Allen, K. Friedman, B.D. Affective learning: A taxonomy for teaching social work values. Journal of Social Work Values and Ethics 7.2, 2010.

[11] Simpson, E. Educational objectives in the psychomotor domain. Behavioral Objectives in Curriculum Development: Selected Readings and Bibliography, 1971.

[12] Vodič za korisnike ECTS-a. http://www.unizd.hr/Portals/0/bolonjski_proces/pdf/Vodic_za_korisnike_ECTS-a.pdf $(10.06 .2015)$ 